\title{
The effect of price on electricity contract choice
}

\author{
Mattias VesterberG*
}

January 22, 2017

\begin{abstract}
I explore how households switch between fixed-price and variable-price electricity contracts in response to variations in price and temperature, conditional on previous contract choice. Using panel data with roughly 54000 Swedish households, a dynamic probit model is estimated. The results suggest that the choice of contract exhibits substantial state dependence, with an estimated marginal effect of previous contract choice of 0.96, and that the short-run effects of variation in prices and temperature on the choice of electricity contract are small. Further, the state dependence and price responsiveness are similar across housing types, income levels and other dimensions. A plausible explanation of these results is that transaction costs are perceived to be larger than the relatively small cost savings from switching between contracts.
\end{abstract}

JEL Codes: Q41, D12, D10, Q48

Keywords: Electricity demand, electricity contract choice, demand flexibility

\section{Introduction}

In this paper, I explore households' choice of electricity contract using unique monthly household data from Sweden. As far as I am aware, this is the first paper to explore this topic using household-level panel data, allowing for a dynamic analysis of electricity contract choice. In more detail, conditional on the previous electricity contract, households are assumed to switch between different contracts in response to variations over time in prices, temperature, and other relevant variables. Consider, for example, a household on a contract with prices varying by month, facing the decision of remaining on the current contract or switching to an alternative contract. If the monthly price increases for some reason, this household might switch to a contract with prices fixed for a year or longer in response to such price variations. If there is no variation in prices or other determinants of contract choice, a household is expected to remain

\footnotetext{
${ }^{*}$ Center for Environmental and Resource Economics (CERE), Umeå School of Business and Economics and Industrial Doctoral School, Umeå University. Email: mattias.vesterberg@umu.se
} 
on its current contract. For example, time-invariant household characteristics may determine the initial choice of contract, but are likely not a reason to switch between contracts. On the other hand, the response to prices may differ across household characteristics. For example, if there exist transaction costs for switching between contracts, high-income households may be more responsive to prices.

Understanding households' choice of electricity contract is important for several reasons. First, understanding the choice between electricity contracts is an important key to understanding residential electricity demand. Wholesale prices and the variability of prices typically differ across contracts, and therefore the short-run price elasticity is also expected to differ across contracts. In more detail, some contracts have prices varying by hour or month and other contracts have prices that are fixed for a year or longer. Throughout this paper, I refer to electricity contracts where the price varies by month as variable-price contracts, and to contracts where the price is fixed for a year or longer as fixed-price contracts ${ }^{1}$ Households choosing the latter type of contract pay a fixed price per $\mathrm{kWh}$ and therefore lack any incentives to respond to short-run (i.e., monthly) price variation. As a result, the short-run price elasticity is expected to differ depending on the type of contract. Understanding the choice between electricity contracts is therefore important in order to understand the price responsiveness of electricity demand.

Further, if peaks in the variable price are associated with an increased probability of choosing a fixed-price contract, the aggregate short-run price responsiveness will decrease if price peaks become more common and more households switch to fixed-price contracts. Although prices in Sweden have been both low and stable since 2011, explained by relatively warm winters ${ }^{2}$ the increasing share of wind power production is expected to affect electricity prices in the future. In particular, Sweden has a rather ambitious climate policy, with a target of 50 percent share of renewable sources in total energy production by 2020, and is currently expanding the share of intermittent production. While rising wind generation does tend to reduce the level of spot prices, ceteris paribus, it is also likely to increase the spot-price variance, both within-day and across seasons (see, for example, Sweco (2016) for Sweden and Astaneh and Chen (2013) for the Nordic market, Woo et al. (2011) for the US and Ketterer (2014) for Germany). Risk-averse households might then switch to fixed-price contracts to avoid this price volatility. On the other hand, more volatile spot prices might also lead to a higher premium for fixed-price contracts, counteracting this effect. Nevertheless, if electricity prices are important determinants of electricity contract choice, we would expect substantial changes in the share of households on each type of electricity contract.

Second, understanding the choice between electricity contracts is also of importance in order to understand the competitiveness of the electricity retail

\footnotetext{
${ }^{1}$ Further, the electricity price refers to the wholesale price unless otherwise stated, and the total price, including taxes and certificate fees, is referred to as the consumer price.

${ }^{2}$ see http://www.energimarknadsinspektionen.se/Documents / Publikationer/rapporter_och_pm/Rapporter\%202015/Ei_R2015_13.pdf
} 
market. Several papers have argued that switching between retailers tends to reduce market power; see, for example, Goett et al. (2000), Ek and Söderholm (2008), Defeuilley (2009) and Gamble et al. (2009). However, in order to understand the competitiveness of the electricity retail market, it is also important to understand determinants of electricity contract choice (Littlechild (2006), Ek and Söderholm (2008) and Defeuilley (2009)). If households are price inelastic and tend to remain on their current contract, for example because of transaction costs, this may allow the retailer to increase prices above the marginal cost of electricity. While the choice of retailer has been studied before, less is known about the choice of contract. In particular, as pointed out by Littlechild (2006), it is of interest to understand how households respond to prices by switching between contracts.

Third, understanding the determinants of electricity contract choice, and in particular the role of prices, can shed light on the potential demand for electricity contracts with hourly pricing. Specifically, a household that today and under current price volatility prefers to pay a price premium to avoid monthly price variation may be unlikely to chose a real-time pricing contract with prices varying by hour. Absent data on households choosing real-time pricing contracts, understanding which factors are correlated with the choice of a fixed-price contract can help policy makers target groups of households that are more likely to be receptive to dynamic pricing of electricity. See, for example, Vesterberg and Kiran B Krishnamurthy (2016) and references therein for a discussion of real-time pricing in Sweden and elsewhere.

This paper adds to the sparse previous literature by being the first (as far as I am aware) to use panel data to explore determinants of the choice between fixed-price contracts and variable-price contracts. Of particular focus is how households switch between contract types in response to variations in economically relevant variables, most notably prices, and to what extent previous contract choices determine current contract. The panel structure of the data allows for dynamic modeling of the contract choice, where households respond to prices, conditional on previous choice of contract. The sparse previous literature on electricity contract choice has used stated preferences to understand the contract choice, whereas this paper addresses this question this from a revealed-preference perspective, i.e., from actual choices.

Although there are many types of contracts available in the Swedish retail market 3 I focus on the choice between contracts with fixed and variable prices for two main reasons. First, because this choice is between certain and uncertain prices, it is related to households' preferences for price certainty. Second, these two type of contracts are by far the most common in Sweden; see Section 2 for a brief description of different types of contracts. Finally, a large majority of the households in the data have one of these two types of contracts, and few households are on other types of contracts.

The data used in this paper originates from one of the larger electricity re-

\footnotetext{
${ }^{3}$ Examples include electricity contracts with prices varying by hour (so-called real time price contracts), electricity contracts where all production comes from renewable sources, and contracts where the price is fixed during the winter but varies by month during the summer.
} 
tailers in Sweden, with a sample size of roughly 54000 households. Using this detailed data, I estimate a random effects probit model with contract choice as the outcome variable and prices, previous choices and temperature as independent variables. Key findings in this paper are that there seems to be a substantial state dependence in contract choice, and that the effect of prices on the choice of contract in the short run is small. A plausible explanation of these results is that transaction costs are perceived as large, relative to potential cost savings from switching between contracts. A number of facts about the Swedish electricity retail market support this explanation. First, the difference in prices between different types of contracts is on average small. Further, the wholesale price constitutes less than half of the total cost of electricity, so any savings from switching between electricity contracts, relative to the total cost of electricity, are expected to be small, on average. Second, electricity is typically a small share of the household budget. Third, many of the household characteristics that may be associated with the choice of contract, such as housing type, heating system and income levels, are fixed in the short run, or vary only by a little.

The rest of this paper is structured as follows: Section 2 gives a short background of the Swedish electricity retail market, as well as a brief review of the literature related to electricity contract choice. Section 3 describes the data used in this paper, and Section 4 describes the empirical framework. Section 5 presents the results, together with robustness analysis, with alternative specifications and estimation frameworks. Section 6 concludes.

\section{Background}

During the 1990s, many European countries, including Sweden, deregulated their electricity markets. In Sweden, this has introduced competition between companies supplying electricity, while transmission distribution is done by local monopolies. This period also marked the beginning of the integration of the Swedish electricity market with markets in the Nordic and Baltic countries via a common spot market. The price of electricity is nowadays determined by supply and demand on the day-ahead and intra-day markets on the Nord Pool power exchange. For a discussion and comparison of the retail markets in the other Nordic countries, see Littlechild (2006). Since deregulation, Swedish households have been free to choose among more than 100 different retailers, each of them offering several different types of contracts. As of late 2014, roughly 40 percent of the households had a variable-price electricity contract, with the price per $\mathrm{kWh}$ varying by month. Another 40 percent had a fixed-price contract, where the price per $\mathrm{kWh}$ is fixed for a year or longer, typically up to five years (source: SCB (2014b)). Households that do not make an active choice of electricity contract are automatically assigned to a so-called default contract with the local retailer. The default price is typically substantially higher than for other contracts (see Figure 2). Still, roughly 15 percent of all households in Sweden have such contracts. 


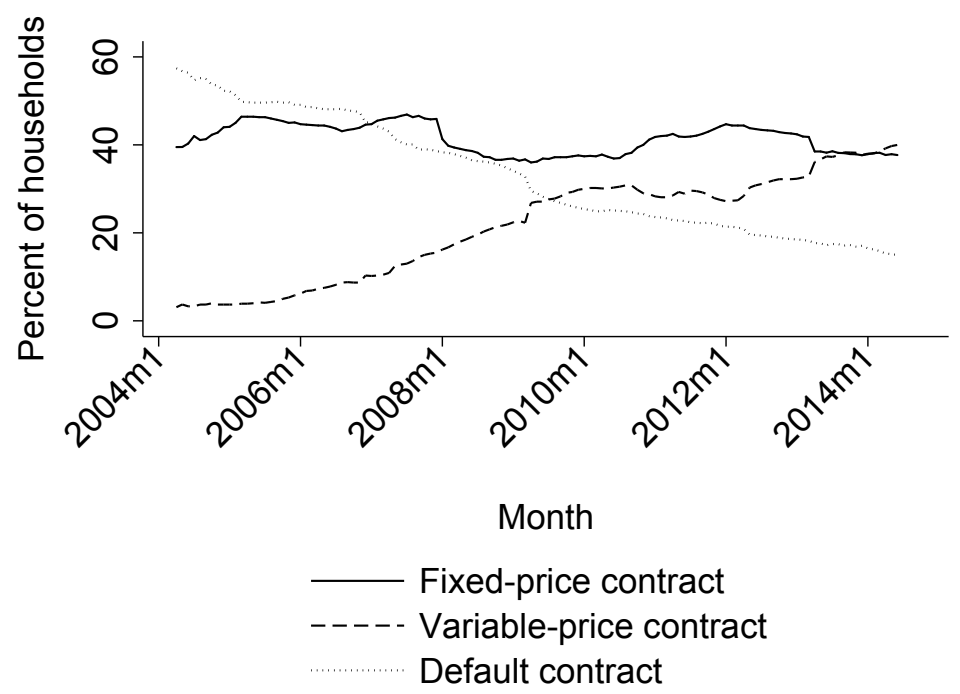

Figure 1: Share of households by contract type. Source: SCB (2014a)

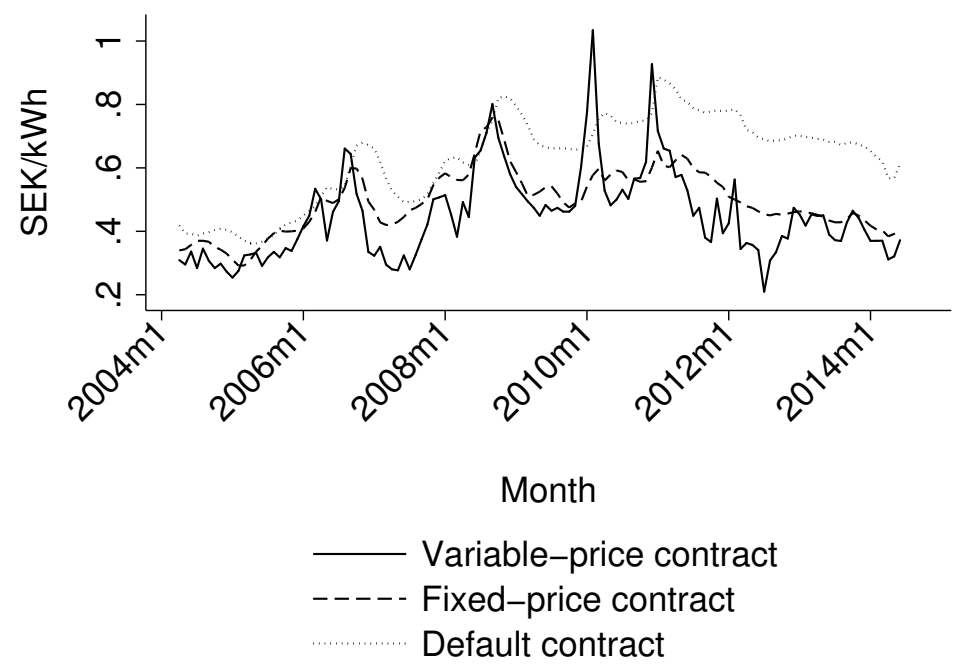

Figure 2: Average prices by contract type. Source: SCB 2014a)

Since 2004, the share of households on default contracts has decreased substantially, while the share of variable-price contracts has increased, and the share of households on fixed-price contracts has remained relatively stable. According to the Swedish Energy Agency, the decreasing share of households on 
default contracts is to a large extent explained by increased awareness among households of the potential cost savings from avoiding such contracts ${ }^{4}$ Also note that the positive trend in variable-price contracts decreased after the winter of 2009/2010, when Sweden experienced high electricity prices (see Figure 2 ), caused by cold temperatures and disruption in some of the nuclear reactors in Sweden.

However, even if there has been a distinct long-run trend in the share of households on different types of contracts, few households switch between contracts in the short run. In particular, even though the last ten years have seen substantial price variation (see Figure 2), and even though several websites provide easily available information about prices and instructions on how to switch between contracts (for example, www.elpriskollen.se and www.elskling.se), households tend to stick to one type of contract in the short run. Between 10 and 20 percent of all households switch contracts each year, with fewer households switching each year (see SCB $(2014 \mathrm{~b})$ ). This relatively small figure might be explained by transaction costs associated with switching between electricity contracts, as suggested by Klemperer (1987), Juliusson et al. (2007), Gärling et al. (2008), Ek and Söderholm (2008), Defeuilley (2009) and Ericson (2011). For example, in a survey by the organization TEMO on behalf of Svensk Energ:5 reasons for not switching between contracts included "lack of interest", "too little gain", "too complicated", "use too little electricity", "hard to choose" and "haven't had time" (TEMO (2005)). Ek and Söderholm (2008) find similar reasons for not switching between retailers. Similarly, the Swedish competition authority argues that households lack sufficient knowledge about how to switch between contracts and/or retailers and that search costs are perceived as larger than potential savings (Konsumentverket (2009)). Also note that, even when there has been substantial price variation for some months, the average monthly price differential is small (roughly 0.04 SEK) and households might perceive potential cost savings from switching between contracts to be smaller than transaction costs. Further, a household that has agreed to a contract where prices are fixed for a given time period has also committed to remain on this contract for the same period of time. If these households want to cancel their fixed-price contract in advance and switch to a different retailer and/or contract, they typically have to pay a penalty, the size of which depends on the time remaining on the contract and the level of electricity usage for that particular household. Households choosing variable-price contracts, on the other hand, are free to switch to another contract without having to pay any such penalty.

Other explanations for state dependence might be habit persistence (i.e., use of a contract causes one to acquire a taste for that contract) and risk aversion (i.e., use of a contract gives one knowledge about its attributes, making it a safe choice on a subsequent choice occasion). It is also important to remember that the price elasticity of electricity typically is small, and recent literature

${ }^{4}$ See http://www.energimyndigheten.se/nyhetsarkiv/2016/allt-fler-elkunder-valjer-avtalmed-rorligt-pris/

"Svensk Energi ("Swedish Energy") is a Swedish industry association consisting of energy producers and retailers. 
has illustrated that households are inattentive to electricity prices and lack perfect information about prices; see, for example, Allcott (2011), Ito (2014), Palmer and Walls (2015) and Kažukauskas and Broberg (2015). If households are inattentive to electricity prices, this might suggest that prices have little influence on electricity contract choice. Finally, for most households, electricity expenditure constitutes only a small proportion of disposable income (Juliusson et al. (2007)). For example, a household living in a villa, using $15000 \mathrm{kWh}$ per year, could have electricity costs corresponding to roughly five percent of yearly per capita income. The potential cost savings from switching between contracts may then be perceived as too small to have any impact on the household's budget.

The fixed price is typically determined by the retailers' forecast of future spot prices. For this type of contract, it is the retailer that carries the price risk and the household agrees to pay a premium for this insurance. Longer contract durations typically correspond to higher prices, reflecting greater uncertainty about the price in the far future. Similarly, more volatility in the spot price corresponds to a higher premium. The variable price varies by month and is based on the spot price on Nord Pool. The most common arrangement is to pay a load-weighted average of the electricity that the retailer has bought during the month. Weighting is typically done hour by hour, where peak hours are given higher weights than off-peak hours.

Average monthly wholesale prices per kWh over all retailers for variableprice contracts, fixed-price contracts and default contracts are illustrated in Figure 2. The price per $\mathrm{kWh}$ is on average higher for fixed-price contracts than for variable-price contracts, as expected, but the price differential is small. During 2004 to 2014, the average price for one-year fixed-price contracts was $0.49 \mathrm{SEK} / \mathrm{kWh}$ and the corresponding figure for variable-price contracts was $0.45 \mathrm{SEK} / \mathrm{kWh}$. The standard deviation for variable-price contracts during this time period was $0.15 \mathrm{SEK} / \mathrm{kWh}$, and the highest price during this period was roughly $1.1 \mathrm{SEK} / \mathrm{kWh}$. It is generally assumed that choosing a contract with variable prices that follow the prices on an energy exchange market would be the most beneficial agreement in the longer term (e.g., Klemperer (1987)). For example, for a villa consuming $15000 \mathrm{kWh}$ per year, the price differential between a fixed-price contract and a variable-price contract corresponds, on average, to a difference in cost of roughly 600 SEK per year or roughly four percent of total electricity expenditure. However, note that, even though the variable price on average has been lower than the fixed price, households may still have lower annual expenditures on a fixed-price contract if price peaks occur when electricity usage is high. Differences in annual expenditure for villas and flats on different contracts, using average monthly electricity usage and prices from the data used in this paper, are calculated and compared in Section 3. Also worth noting is that cost savings are argued to be larger from switching between contracts than from switching between retailers (Littlechild (2006)).

In addition to the wholesale price per $\mathrm{kWh}$, the consumer price of electricity (irrespective of contract) includes the energy tax (roughly $0.4 \mathrm{SEK} / \mathrm{kWh}$ ), the electricity certificate fee $(0.03 \mathrm{SEK} / \mathrm{kWh})$, sales tax $(25 \%)$ and a transmission 
fee. This transmission fee has a variable part, which is roughly $0.1 \mathrm{SEK} / \mathrm{kWh}$, and a fixed part, which varies between roughly 1500 SEK and 15000 SEK per year, depending on the size of the household's fuse amp. It is important to note that taxes, the certificate fee and transmission fees constitute a large part of the total cost of electricity. As a consequence, households choosing a variable-price contract only have short-run variation in the wholesale price per $\mathrm{kWh}$, which is roughly half of the total costs of electricity on average. The development of the consumer price (including taxes and certificate fees) by year is illustrated in Figure 3. Evidently, the consumer price has increased substantially over time, mostly explained by higher taxes and the introduction of EU-ETS and certificate fees.

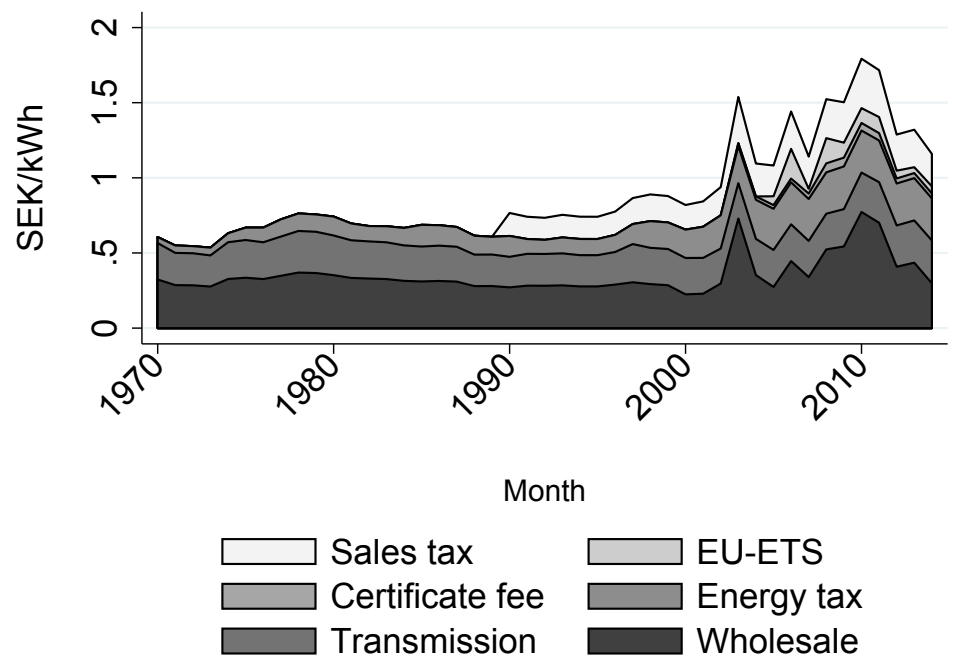

Figure 3: Consumer price development over time (yearly data)

Only a few studies in the very large literature on electricity demand have explored how prices influence the choice of electricity contracts. Further, as noted previously, all previous studies use stated preferences to understand households' choice of electricity contracts, and are unable to estimate any effect of current or previous prices on actual contract choice. Goett et al. (2000) and Juliusson et al. (2007) both find that households are willing to pay a price premium to avoid price variation. In more detail, Goett et al. (2000) find, for the US, that households dislike hourly price variation in particular, and that hourly rates on average would need to be roughly 0.039 USD per kWh lower than under a fixedprice rate in order to compensate for the variability of hourly rates (the average fixed price was roughly 0.1 USD per $\mathrm{kWh}$ ). For seasonal rates, the compensation required by households was 0.008 USD per kWh. Juliusson et al. (2007) analyze how loss aversion and beliefs about future price volatility affect the probability 
of choosing a variable-price contract, using Swedish survey data. They find that both loss aversion and concerns about price volatility are negatively correlated with attitudes towards variable-price contracts.

In addition to prices, household characteristics and electricity usage may influence the choice of electricity contract. For example, Ericson (2011) finds that floor area, which typically is positively correlated with electricity usage, decreases the probability of preferring a variable-price contract. The explanation for this might be that households with high electricity usage feel more vulnerable to price variation and are therefore more likely to choose electricity contracts with fixed prices, if they are risk averse. Consider two households with similar characteristics such as income, family size and location, but with one household using more electricity. This could be the case if one household has electric heating and the other district heating. The household with high electricity usage will then face larger increases in expenditure on electricity in case of price peaks. Assuming they have similar risk preferences, we would expect this household to be more likely to choose a fixed-price contract ${ }^{6}$ Figures from SCB (2014b) seem to support this, as illustrated in Table 1. In particular, roughly half of the households with a high level of electricity usage have chosen fixedprice contracts. For households with a lower level of usage, the corresponding figure is roughly 36 percent.

Note that electricity usage can be seen as a function of outdoor temperature, heating system and other household characteristics such as income and number of people living in the household, so all these variables are expected to affect the choice of contract via electricity usage. Also note that some household characteristics may have a separate effect on the choice of electricity contracts. For example, households with high income can more easily afford peaks in the variable price. Somewhat surprisingly, Juliusson et al. (2007) find no significant effect from either income or electricity expenditure, but age and education are shown to have negative and significant impacts on preferences for variable-price contracts. It is important to note that many of the household characteristics that might be associated with the choice of electricity contract, such as housing type and heating system, typically are fixed in the short run, which might explain why households remain on the same contract in the short run. Similarly, the variation in socio-economic characteristics, such as income, are expected to be small on average in the short run. As such, the fact that many household characteristics plausibly associated with the choice of electricity contract are fixed in the short run may be another explanation of the seemingly large state dependence, where households remain on the same contract in the short run. However, it might very well be the case that the response to, e.g., prices, differs across such household characteristics, as discussed in the introduction. For example, a household with a high level of electricity usage may be more responsive to prices because it will face larger increases in its electricity bill in case of price peaks.

Finally, the choice of electricity contract shares some characteristics with

\footnotetext{
${ }^{6}$ Also note that a similar argument can be made for variations in temperature. If a household feels vulnerable to variations in both prices and temperature, it may be more likely to choose a fixed-price contract to avoid one of these sources of uncertainty.
} 
Table 1: Share of households on different electricity contracts by annual consumption

\begin{tabular}{lrrrr}
\hline \hline Percent of households in the & & & & \\
sample on each contract type & $2000-5000$ & $5000-10000$ & $10000-20000$ & $20000-$ \\
\hline Default contract & 24.4 & 9.9 & 6.5 & 9 \\
Variable price & 36.3 & 40.6 & 37.7 & 37.2 \\
Fixed price & 36.6 & 43.9 & 48.3 & 48.3 \\
Other & 2.7 & 5.6 & 7.5 & 5.5 \\
\hline \hline
\end{tabular}

Notes: i) Source: $\mathrm{SCB}(2014 \mathrm{~b})$.

ii) "Fixed price" refers to contracts with prices fixed for a year or longer, "Variable price" refers to contracts with prices varying by month and "Default contract" refers to the type of contract to which households automatically are assigned if they do not make an active choice (see Section 2). "Other" refers to other types of contracts, including real-time pricing and contracts where the price is fixed for some months and variable for other months (so-called mixed contracts). 
other, more frequently studied choices. For example, the choice between fixedprice and variable-price contracts bears similarities to the choice between an adjustable-rate mortgage and a fixed-rate mortgage; see, for example, Dhillon et al. (1987) and Campbell and Cocco (2003). The overall conclusion from these studies is that households in general dislike variation in their mortgage rate, and are willing to pay a premium to avoid it. Interestingly, Paiella and Pozzolo (2007) find that that most household characteristics are irrelevant for the choice between an adjustable-rate mortgage and a fixed-rate mortgage and that the main determinants are the relative price of the mortgages and whether the household is liquidity constrained.

\section{Data}

The data used in this paper is the customer database of Skellefteå Kraft, one of the larger electricity retailers in Sweden (see www.skekraft.se). The source material has been anonymised and identification of unique households is not possible. With data on households from only one supplier out of many in Sweden, there is the obvious risk that the data used in this paper is not representative of the Swedish population, and that the results cannot readily be generalized to households choosing between electricity contracts from other suppliers. However, I argue that the choice between fixed-price and variable-price contracts from Skellefteå Kraft is expected to be similar in most aspects to corresponding choices from other retailers. Most importantly, the electricity retail market in Sweden is a competitive market, and retailers are assumed to be similar in terms of prices and other contract attributes (Littlechild (2006)). The choice between different contract types from this particular retailer is therefore assumed to be comparable to the choice between contracts from other retailers, and the qualitative results from this study are assumed to hold for most of Sweden. However, some caution is appropriate when interpolating the results of this study to the rest of the Swedish population.

The data consist of an unbalanced panel with monthly observations on 54548 households in total, of which 42517 are villas and the remainder are flats. These households are observed from May 2010 to June 2014. As is illustrated in Figure 4. most of the households in the data are located in the northern part of Sweden, whereas the Swedish population is concentrated in the middle and south of Sweden. This is expected, because one important determinant of retailer choice is assumed to be geographical location and closeness to the retailer. For example, Goett et al. (2000), Revelt and Train (2000) and Yang (2014) demonstrate that households prefer their local company to any other retailer.

37549 of the households in the data have had a fixed-price contract at some point during the sample period, and 22641 households have had a variableprice contract. The average contract duration for fixed-price contracts is 16 months. Skellefteå Kraft is one of few retailers in Sweden that do not offer default contracts, so the data only includes households on variable-price contracts or fixed-price contracts. Figure 5 illustrates the share of households on 


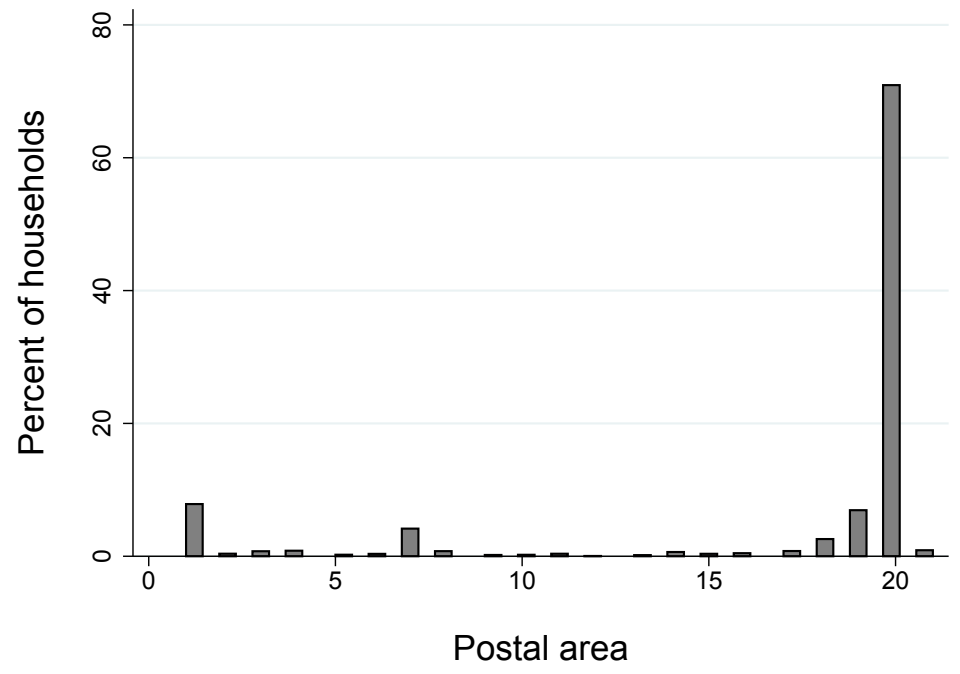

Figure 4: Location of households. Postal area 1 is Stockholm, postal area 7 is Gothenburg, postal area 19 is Umeå and postal area 20 is Lulea (which includes Skelleftea, the location of the retailer).

fixed-price contracts in the data over time, together with the relative prices of variable-price contracts and fixed-price contracts. Although the data cover the period July 2010 to June 2014, data on prices is available before this period as well.

It is evident from this figure is that the share of households on fixed-price contracts in the data increased substantially during late 2010 and during 2011. Comparing the relative price between variable-price contracts and fixed-price contracts, this period was associated with large variation in the relative price. Since then, the share of households on fixed-price contracts has been rather stable at around 75 percent. This is higher than the corresponding figure for the population, as illustrated in Figure 5. One possible explanation is that households living in relatively cold regions of northern Sweden, where a majority of the households in the data are located, might be more likely to choose a fixed-price contract, since these household have relatively high electricity usage (because of more electricity needed for heating) and therefore might feel more vulnerable to variations in the price.

To explore transitions between fixed-price contracts and variable-price contracts, Figure 6 illustrates transitions per month as a share of total number of households, together with the relative price of the two contract types (variable price divided by the fixed price). In general, households are expected to switch from fixed-price contracts to variable-price contracts when the relative price is low, and in the other direction when the relative price is high. Roughly 11 percent of all households have switched between fixed-price and variable-price con- 


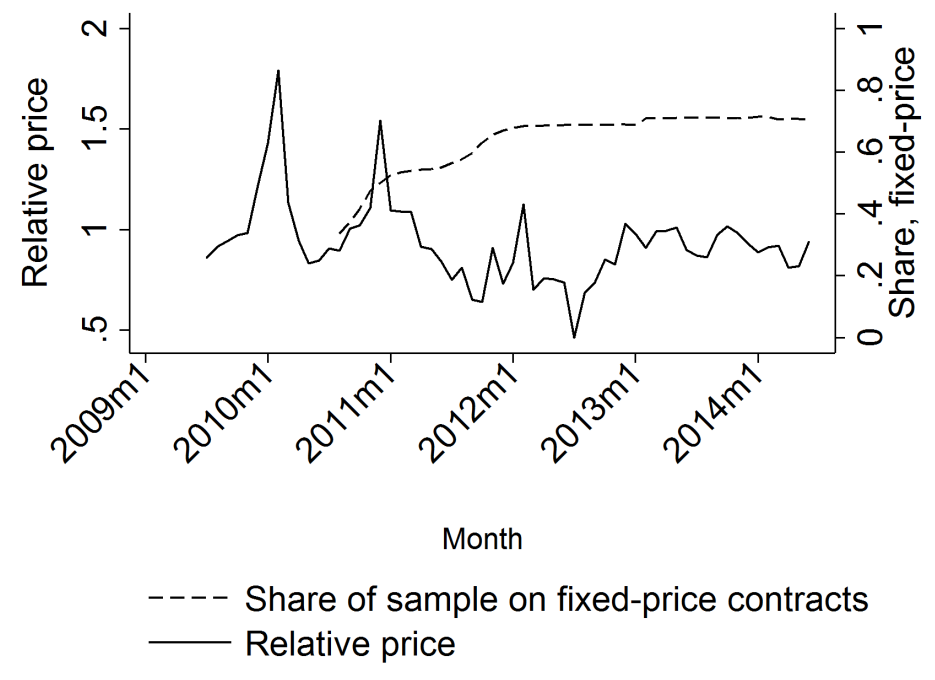

Figure 5: Share of households on fixed-price contracts over time, together with the relative price between variable-and fixed-price contracts (the average variable price divided by the average fixed price).
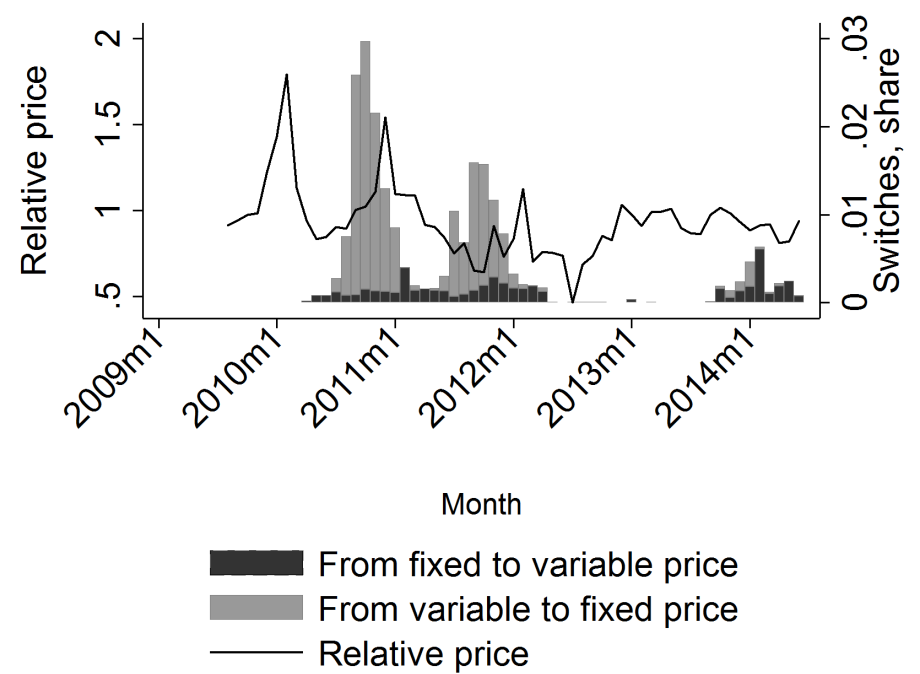

Figure 6: Share of households switching between the two type of contracts per month, together with the relative price (the average variable price divided by the average fixed price). 
tracts, with a total of 6022 transitions. A majority of these transitions are from a variable-price to a fixed-price contract, and only 1139 transitions are in the other direction. Recall from Section 2 that households on fixed-price contracts also agree to remain on their contract for as long as the price is fixed, typically between one and five years. Therefore, it is not surprising that relatively few households switch from fixed-price contracts to another type of contract. All households that switch from a fixed-price contract to a variable-price contract do so at the end of their contract period.

Most switches occurred during 2010 and 2011, with virtually no switches during 2013. The number of switches peaked during October 2010 with roughly 800 switches, corresponding to roughly three percent of the households in the data that month. Further, there is a distinct pattern in the switches between contract types, with most of the switches from variable-price contracts to fixedprice contracts occurring some months after peaks in the relative price (with the switch typically occurring in the latter part of the year). This suggests that households switch to fixed-price contracts as insurance against price peaks during the coming winter, and do so if the variable price was high relative to the fixed price during the previous winter. The small number of switches during 2013 might appear surprising, since households would benefit from switching from fixed-price contracts to variable-price contracts when the relative price was below unity. As discussed above, one explanation might be that households on fixed-price contracts face costs if they want to switch contracts before the expiration of their current contract. The switches during the winter 2013/2014 occurred even though the relative price during the previous winter was close to unity. One explanation for households switching from fixed-price contracts to variable-price contracts might be that the variable price had been rather stable for a year, and that households perceived the price risk associated with variable-price contracts as small. The switches from variable-price contracts to fixed-price contracts during the same period might be explained by unusually high prices during the summer of 2013, which might have affected households' expectations of the price. In addition, the winter months of 2014 saw some unusually cold days, which might also have contributed to expectations of high variable prices, which could explain the switches.

In addition to contract choice, the data includes information about monthly electricity usage in $\mathrm{kWh}$ and prices per month, zip-code, housing type (villa or flat) and heating system (electric heating or not). Unfortunately, the data lacks any household-level information about income and other household characteristics, but it includes information about income, age and education at the zip-code level, with figures from 2014. For the whole of Sweden, the average number of persons in each zip-code is 918, allowing for precise neighborhood matching with census data. Matching individual-level data with zip code-level data is frequently used in economics, including studies on residential electricity demand (for example, Borenstein (2012) and Ito (2014)). However, the lack of variation over time poses some challenges for the estimation. Several ways of addressing this are discussed in Section 5. Finally, average monthly temperature by postal area level is obtained from SMHI (Swedish Meteorological and 
Hydrological Institute; see SMHI.se).

Summary statistics by contract choice for the variables used in this paper are illustrated in Table 2. I present these statistics for all households in the data and also separately for the two type of contracts. However, note that a household may have had both types of contracts, and may therefore be included in both categories in this table.

As already noted, a large majority of the households in the sample are living in villas, and roughly 22 percent are living in flats. This is likely explained by the fact that a large proportion of the households in the data are located in relatively small cities in northern Sweden, where villas are more common. To a large extent, electrically heated villas have fixed-price contracts, whereas variableprice contracts are more common among flats. As already noted, this might be explained by households living in villas having a higher level of electricity usage, and therefore feeling more vulnerable to peaks in the variable price. Secondly, the annual per capita income is somewhat smaller than the population average of roughly 300000 SEK (roughly 25000 Euro). Again, this is explained by the geographical location of the sample, with northern Sweden having lower income than metropolitan areas, for example the Stockholm area. Further, households choosing a variable-price contract have, on average, higher income, as expected. Age is somewhat higher than the population average of 41.2 years, whereas family size and education level correspond roughly to population figures. Both age and family size are very similar across contract types, whereas households with variable-price contracts to a larger extent have a university degree.

Turning to electricity usage, the average electricity usage per month for an electrically heated villa is $1495 \mathrm{kWh}$. These figures are somewhat smaller than those reported by the Swedish Energy Agency for an average villa (see Energimyndigheten, 2014). The corresponding figure for a flat is $364 \mathrm{kWh}$. Flats typically lack individual heating systems, explaining the large difference in usage compared to villas. The standard deviation of the mean of electricity usage illustrates substantial variation, across households and, in particular, across housing types, but also shows seasonal variation. See Vesterberg and Kiran B Krishnamurthy (2016) for a detailed description of end-use-specific usage for residential electricity demand in Sweden. For both flats and villas, households with fixed-price contracts use more electricity than do households with variableprice contracts.

To compare electricity expenditures on each type of contract for the average electrically heated villa and the average flat in the data, I calculate annual expenditures by multiplying the average monthly electricity usage by the average monthly variable price and the average fixed price, separately for each housing type. I then compare the annual costs of each type of contract. These calculations reveal that the cost differential between the two types of contracts is small relative to total expenditure: for an average flat (using roughly $4200 \mathrm{kWh}$ per year), the average annual cost differential amounts to only 150 SEK or roughly four percent of annual expenditure (including taxes, transmission fees, etc.). The corresponding figure for an average electrically heated villa (using roughly $18000 \mathrm{kWh}$ ) is 530 SEK or roughly three percent of annual expenditure. This 


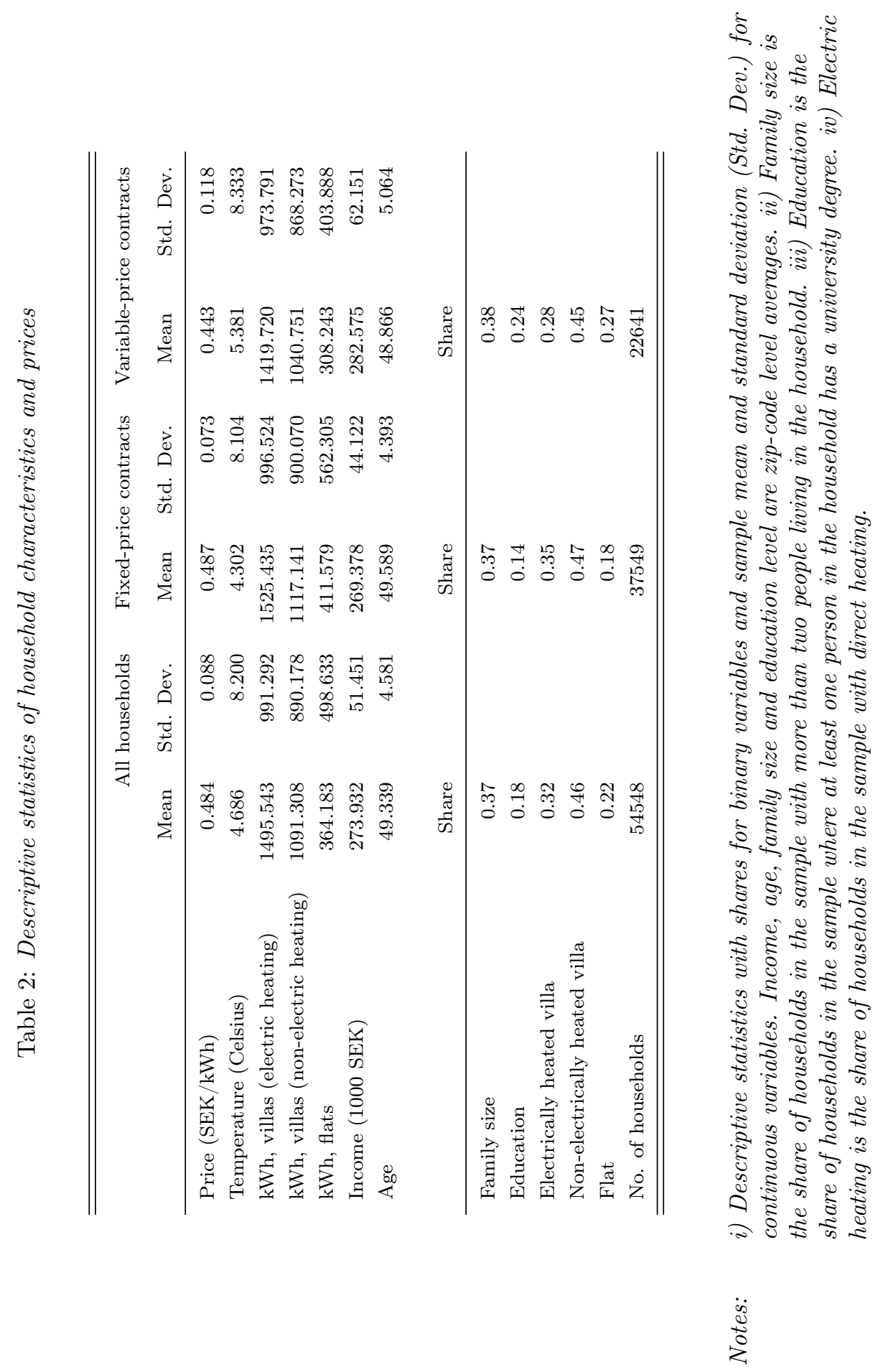


suggests that, on average, the cost savings from switching between electricity contracts are expected to be small.

\section{Econometric model}

There are several reasons that electricity contract choice should be characterized as a dynamic choice problem. To the extent that households form beliefs about future prices and plan their current decisions in response to these beliefs, the choice of contract may be inherently dynamic. Further, as described in Section 2 for the population and in Section 3 for the sample, there seems to be substantial persistence in contract choice in the short run, with most households remaining on one type of contract. There are a myriad of plausible explanations for such a link between current and past behavior, as discussed in Section 2. Even though there may be many different sources of state dependence, distinguishing between these sources is outside the scope of this paper and would require a more elaborate structural approach. Rather, this paper should be viewed as establishing a baseline for further research on this topic. However, some sensitivity analysis is provided in Section 5 where I elaborate on the fact that households on fixed-price contracts face a penalty if they want to switch before the end of the contract period, and how I discuss this might affect the results.

Let $y_{i t}=1$ denote the choice of a fixed contract and $y_{i t}=0$ the choice of a variable-price contract for household $i$ at time $t$. A dynamic random effects probit model describing the choice problem is then

$$
f_{i t}\left(y_{i t} \mid y_{i t-1}, \mathbf{z}_{i t}, \alpha_{i} ; \theta\right)=\Phi\left(\mathbf{z}_{i t} \gamma+\lambda y_{i t-1}+\alpha_{i}\right)
$$

where $i=1, \ldots, N$ indexes household, $t=0$ indexes the initial condition and $t=1, \ldots, T$ index time for the rest of the observations. $\mathbf{z}_{i t}$ is a vector of observed household characteristics and contract attributes. $y_{i t-1}$ is the contract choice in the previous period and $\alpha_{i}$ is an unobserved household-specific effect that is time-invariant. Equation 1 contains two assumptions. First, the dynamics are first order, once $\mathbf{z}_{i t}$ and $\alpha_{i}$ are also conditioned on, and second, the unobserved effect $\alpha_{i}$ is additive inside the standard normal cumulative distribution function $\Phi$. In addition, the random effects probit model assumes that $\alpha_{i} \mid \mathbf{z}_{i t} \sim N\left(0, \sigma_{\alpha}^{2}\right)$, which is a strong assumption because it requires that $\alpha_{i}$ and $\mathbf{z}_{i t}$ are independent (Wooldridge, 2010). I will get back to this issue later, and will illustrate how the method of dealing with the initial conditions problem introduces a way of relaxing the independence assumption between $\alpha_{i}$ and $\mathbf{z}_{i t}$ in the random effects $\operatorname{model} 7$

Treating the initial condition as a nonrandom constant assumes that the initial contract choice is independent of unobserved heterogeneity, containing, for example, preferences and risk aversion. This is obviously a strong assumption,

\footnotetext{
${ }^{7}$ An alternative approach would be the conditional fixed effects logit model (Chamberlain 1980). However, such a model requires within-household variation in the dependent variable and, because only 11 percentage of the households have made a transition, such a model cannot use all data.
} 
and a more reasonable approach is to think of the initial condition as endogenous and specify a conditional distribution for the initial condition. Wooldridge (2005) suggests using a reduced-form approach where the unobserved householdeffects are conditioned on the initial values and the exogenous variables (see also Akay, 2009, Stewart, 2007, Arulampalam and Stewart, 2009, Rabe-Hesketh and Skrondal, 2013 and Skrondal and Rabe-Hesketh, 2014) $\left.\right|^{8}$ Wooldridge (2005) defines the auxiliary model for the unobserved individual effects as

$$
\alpha_{i}=\xi_{1} y_{i 0}+\mathbf{z}_{i}^{+} \xi_{2}+\vartheta_{i}
$$

where $\mathbf{z}_{i}^{+}=\left(\mathbf{z}_{i 1}, \ldots, \mathbf{z}_{i T}\right)$ and $\vartheta_{i}$ is a new unobserved household effect which is assumed $\vartheta_{i} \sim \operatorname{iidN}\left[0, \sigma_{\vartheta}^{2}\right]$. However, this specification does not work very well with unbalanced panels. In particular, Wooldridge's specification requires a separate parameter vector for the time-varying co-variates on each occasion and, in case of missing observations, complete-case analysis (or list-wise deletion) because a complete set of co-variate values is required across all occasions. A more plausible specification for unbalanced panels, as suggested by Rabe-Hesketh and Skrondal (2013) and Skrondal and Rabe-Hesketh (2014), is to define the unobserved individual effects to be a function of the initial condition $y_{i 0}$ together with the initial values and the within-means of the time-varying variables in $\mathbf{z}_{i t}$,

$$
\alpha_{i}=\xi_{1} y_{i 0}+\xi_{2} \overline{\mathbf{z}}_{i}+\xi_{3} \mathbf{z}_{i 0}+\vartheta_{i}
$$

where $\overline{\mathbf{z}}_{i}=1 / T \sum_{t=1}^{T} \mathbf{z}_{i t}$. Note that $\mathbf{z}_{i 0}$ is excluded from $\overline{\mathbf{z}}_{i}$.

Thus, we obtain a conditional likelihood which is based on the joint distribution of observations conditional on initial values. The log-likelihood function to be maximized is

$$
\mathcal{L}(\theta)=\sum_{i=1}^{N} \log \left[\int_{-\infty}^{\infty}\left(\prod_{t=1}^{T} \Phi\left(\mathbf{z}_{i t} \gamma+\lambda y_{i t-1}+\left(\xi_{1} y_{i 0}+\xi_{2} \overline{\mathbf{z}}_{i}+\xi_{3} \mathbf{z}_{i 0}+\vartheta_{i}\right)\right)\right)\left(d \vartheta_{i}\right)\right]
$$

which can be estimated using standard random effects probit software. RabeHesketh and Skrondal (2013) show that the inclusion of $\mathbf{z}_{i 0}$ in Equation 3 reduces possible finite-sample bias to negligible levels, and Arulampalam and Stewart (2009) illustrate that the Wooldridge approach yields estimates similar to alternative ways of specifying the initial condition.

\footnotetext{
${ }^{8}$ An alternative approach to Wooldridge (2005) is to use the two-step approach suggested by Orme (1999) and to include the generalized residual from a probit of the initial choice. Zipcode level averages of household characteristics could then be used as instruments in the first stage. However, Skrondal and Rabe-Hesketh (2014) illustrate how this model is dependent on restrictive assumptions for identification, and recommend against using it. Heckman (1981) suggests another alternative framework, but it is known to be computationally heavy and hard to implement, especially with unbalanced panels. Arulampalam and Stewart (2009) provide a simplified implementation of the Heckman (1981) model, but the model generally implies a more restrictive covariance structure for the total errors and is not equivalent to Heckman's model unless T $=3$ (Skrondal and Rabe-Hesketh (2014)). However, it is relatively straightforward to estimate the Heckman model with a balanced panel (e.g., the redprob command in Stata, as implemented by Stewart (2006)), and the results of such estimation for a balanced subset of the data are compared and discussed in Section 5
} 
Finally, recall that the random effects probit model assumes $\alpha_{i} \mid \mathbf{z}_{i t} \sim N\left(0, \sigma_{\alpha}^{2}\right)$ which, in many cases is a strong assumption. In particular, because several economically relevant time-invariant variables are unobserved in the current data, this assumption is likely to be violated. Chamberlain (1980) allow for correlation between $\alpha_{i}$ and $\mathbf{z}_{i t}$ by modeling this relationship as $\alpha_{i} \mid \mathbf{z}_{i t} \sim N\left(\psi+\overline{\mathbf{z}}_{i} \xi, \sigma_{a}^{2}\right)$, where $\overline{\mathbf{z}}_{i}$ is the group average of $\mathbf{z}_{i t}$, as in Equation 3 , and $\sigma_{a}^{2}$ is the variance of $a$ in the equation $\alpha_{i}=\psi+\overline{\mathbf{z}}_{i} \xi+a_{i t}$, i.e. the conditional variance of $\alpha_{i}$. Intuitively, the individual differences that are left may be more plausibly assumed to be independent of observed characteristics; see Mundlak (1978) and Chamberlain (1980). Now, note that the method of dealing with the initial condition outlined above (see Equation 3 already accommodates such correlation by including the group means of $\mathbf{z}_{i t}$ (Skrondal and Rabe-Hesketh, 2014).

As noted already, the resulting estimator is a conditional maximum likelihood estimator, and interpretation of the estimated parameters should be made accordingly. In particular, the estimated marginal effects are to be interpreted as conditional on the initial choice of contract, as well as initial values of the exogenous variables in $\mathbf{z}_{i t}$. This interpretation is appropriate when exploring the topics in this paper, such as the response to prices that vary over time, but would be less well-suited if the aim were to understand, for example, the initial choice of contract. While exploring the latter might be of interest, it is outside the scope of this paper. In addition, any exploration of the initial contract choice for a particular household would face the problem of left censoring, because households are only observed from a given date but likely had a contract before the data period. Therefore, I only observe the initial contract for this particular spell of data, and any choices made prior to that are unobserved. Finally, exploring the initial choice would be more interesting if more data on household characteristics were available at the household level.

The probability of choosing a fixed-price contract is expected to decrease with higher fixed prices, and to increase with higher variable prices. Because of ex-post billing, the variable price at time $t$ is unknown to the household at time $t$, so households are assumed to base the contract decision on the variable price at time $t-1$. Prices are assumed to be exogenous to the individual household. In Sweden, households typically face constant marginal prices, as compared to the more common increasing-block-pricing structure found in, e.g., the US. Further, a household buying electricity on the Nordic market is assumed too small to be able to affect the equilibrium electricity price determined by aggregate demand and supply. Therefore, the price is assumed to be exogenous in line with previous literature on household-level electricity demand in the Nordic market (e.g., Nesbakken (1999) and Krishnamurthy and Kriström (2015)). All prices are in SEK $/ \mathrm{kWh}$.

As discussed in Section 2 households with high electricity usage, such as villas with electric heating, might feel more vulnerable to price variation, and therefore more likely to choose fixed-price contracts. However, including electricity usage as an explanatory variable is not feasible. For example, unless households are completely price inelastic, electricity demand depends on contract choice via prices, since the price per kWh the household pays is determined 
by the choice of contract. A solution to this endogeneity problem is to consider electricity usage as divided into two parts: baseline demand and short-run deviations from this baseline demand. The baseline demand is assumed to be a function of the characteristics of the house, e.g., housing type and heating system, number of persons living in the household, income and the living area size. A short-run deviation from this baseline usage, referred to as residual demand, is assumed to be a function of time-varying variables such as temperature and price.

Because the household characteristics associated with baseline demand typically are fixed in the short run, so is the baseline demand. In particular, baseline demand is assumed not to be a function of prices and therefore of contract choice, and therefore inclusion of baseline demand as an explanatory variable for contract choice does therefore not lead to any simultaneity bias. A reduced-form approach is then used to account for the residual demand, where only the exogenous variables price and outdoor temperature are included as explanatory variables, but not the actual realization of residual demand $9^{9}$ However, households may still differ in price responsiveness across usage levels, as already discussed. To explore this, I estimate the model outlined above separately for different housing types and heating systems: electrically heated villas, non-electrically heated villas and flats.

Further, some household characteristics that are likely associated with baseline demand, such as income, might have a separate effect on the choice of electricity contract, because high-income households can better afford to face the risk of price peaks and therefore are assumed more likely to choose a variableprice contract. On the other hand, Juliusson et al. (2007) find no significant effect of income on preferences for variable-price contracts. Unfortunately, as already alluded to in Section 3, the available measurement of income is timeinvariant, and the model outlined above cannot identify the effect of timeinvariant household characteristics (Wooldridge (2005)). However, income does not typically vary much in the short run, and even if the data included zip-code level income that varied over time, most variation in income over time is common to all regions (see http://www.scb.se/). Also note that matching the household level data with survey data does not solve the problem of time-invariant household characteristics unless repeated surveys are collected for every year of the data period; if most variation in income over time is common to all households, such a variable would not add much information.

Further, note that the income variation that is common to all households is accounted for by year dummy variables. Regional differences in variation in income over time can be accounted for by including interaction terms between variables, e.g., between year and postal area. Ideally, year by zip-code dummies

\footnotetext{
${ }^{9}$ An alternative approach would be to consider the choice of contract and the demand for electricity as a simultanous discrete-continous choice, but as far as I am aware no straightforward implementations of such frameworks exist when the discrete choice is dynamic. Further, given that previous literature has found price elasticities of electricity demand to be close to zero, any adjustments of electricity usage in response to contract choice is most likely small, and would not change the qualitative results in this paper.
} 
would be used, but that would involve fitting roughly $6500 \times 5$ dummy variables. Obviously, region-by-year dummy variables capture not only variation in income but everything that is specific to regions. In addition, even if the model is unable to identify the effects of time-invariant household characteristics, separate models for each income group can be estimated and results can then be compared in order to explore possible heterogeneity in price responsiveness and state dependence across income levels. These different approaches to accounting for income are explored in Section 5.

Month and year dummy variables are included to capture trends and seasonal effects that are common to all households. Finally, time averages and initial values of all independent variables, together with the initial choice of contract, are included to account for the initial condition. Note that any attempts to account for attributes that are specific to one type of contract run the risk of causing complete or quasi-complete separation because such a variable predicts the outcome perfectly.

\section{$5 \quad$ Estimation and Results}

The model outlined in Section 4 can be estimated using standard econometric software, in this case xtprobit in Stata/SE 14. The likelihood function is maximized using the mvaghermite algorithm (mean and variance adaptive Gauss-Hermite algorithm). Results for the main specification, with estimated coefficients and average marginal effects and associated standard errors, are found in Table 3 . Several other specifications and models are explored and discussed.

As is illustrated in Table 3 , there is substantial state dependence, with the probability of choosing a fixed-price contract increasing by roughly 96 percent if the household had a fixed-price contract in the previous choice period. Given the few transitions and that the share of households on fixed-price contracts is fairly constant over time, implying that households tend to remain on their contract type, this is expected. Similarly, the probability of choosing a variable-price contract is very large conditional on a variable-price contract as the previous contract.

Because the state dependence is substantial, and few households switch between contracts, this essentially means that previous contract choice is a very good predictor of current contract choice in the shortrun, and the short-run predictive power of the model is high. This is illustrated in Figure 7, where the average predicted probability of choosing a fixed-price contract from the main specification is plotted together with the share of households on fixed-price contracts for each month. For comparison, the corresponding predicted probabilitiy from a random effects probit model without the lagged dependent variable (and without the initial condition variables) is included. For illustrative purpose, the relative price is also included. Evidently, the main specification has high predictive power, whereas the predictions from the model without the lagged dependent variable are not as close to the true proportion. 
Table 3: Results of the dynamic random effects probit model with electricity contract (fixed price $=1$ ) as dependent variable

\begin{tabular}{rrrrr}
\hline \hline & Coeff. & Std. Error & dy/dx & Std. Error \\
$y_{t-1}$ & 5.532 & 0.025 & 0.965 & 0.003 \\
Temperature & -0.022 & 0.002 & -0.000 & 0.000 \\
Fixed price (SEK/kWh) & -5.225 & 0.425 & -0.036 & 0.003 \\
Variable price (SEK/kWh) & 0.018 & 0.089 & 0.001 & 0.001 \\
Month dummies & Yes & & Yes & \\
Year dummies & Yes & & Yes & \\
Initial condition variables & Yes & & & \\
\hline & & & & \\
Log-likelihood & -34444.063 & & & \\
No of obs & 0.278 & & & \\
Average T & 1677405 & & & \\
No of households & 54548 & & & \\
\hline \hline
\end{tabular}

Notes: i) Coeff. is the estimated coefficient, Std. Error is the associated standard error and $d y / d x$ is the estimated average marginal effect. $d y / d x$ for factor levels is the discrete change from the base level. ii) $\rho$ is the proportion of the total variance contributed by the panel-level variance component. A likelihood-ratio test of $\rho=0$ is able to reject the null-hypothesis, suggesting that the panel-level variance component is important and that the panel estimator is different from a pooled estimator. 


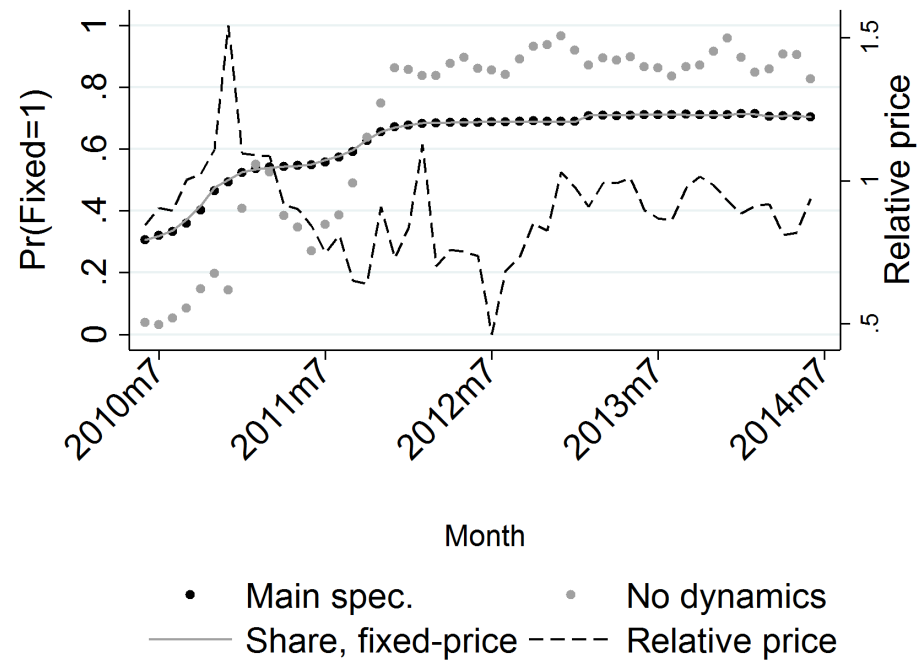

Figure 7: The average predicted probability of choosing a fixed-price contract. The solid line illustrates the share of households in the data on fixed-price contracts. The black dots illustrate predicted probabilities from the main specification, the gray dots illustrate predicted probabilities from a specification without the lagged dependent variable (no dynamics), and the dashed line illustrates the relative price (the average variable price divided by the average fixed price). 
Given the state dependence, it comes as no surprise that the estimated immediate effects of prices are relatively small, albeit statistically significant. For example, a 0.5 SEK increase in the variable price (which corresponds to roughly three standard deviations) only increases the probability of choosing a fixed-price contract by less than one percent. Similarly, the marginal effect of the fixed price is small, albeit somewhat larger than the marginal effect of the variable price. The large effect of the lagged dependent variable suggests that prices have long-run effects. However, exploring long-run effects of prices in a non-linear model is non-trivial, and is outside the scope of this paper. The effect of temperature is negative, but close to zero. Recall that it is assumed that variations in electricity usage are to a large extent determined by prices and temperature, and both these variables have little effect on the choice of contract. This might then suggest that short-run variation in electricity usage has little effect on the choice of contract. In addition, recall that previous literature on electricity demand typically finds the price elasticity of electricity to be small, and in many cases close to zero. The results presented here are in line with such findings.

There are several possible explanations for the substantial state dependence and lack of price responsiveness found in this paper. First, the difference in prices between the two contract types is on average small. Similarly, the shortrun variation in many of the variables plausibly associated with the choice of contract, such as housing characteristics and income levels, is small on average. Second, because electricity expenditure typically is a small share of the budget, households may pay little attention to cost-saving measures. Third, households may perceive information regarding different contracts as hard to understand, and may believe that switching between contracts is complicated. The potential cost savings from switching between contracts are then most likely perceived to be small relative to potential monetary and non-monetary transaction costs associated with switching between contracts. With this in mind, these results appear very intuitive.

As discussed previously, several ways of accounting for possible effects of income are explored. In the main specification, year dummy variables account for variation in income over time that is common to all households. Further, I have estimated the model using interaction terms between year and postal area to control for regional differences in income over time. In short, results are very similar to the main specification in Table 3. In particular, state dependence is substantial and the effect of prices is small. Further, I have estimated the model for separate income groups, using the zip-code level income groups to divide the data into groups, where income group one has the lowest income and income group ten has the highest (a table with per-capita income can be found in the Appendix). While such an analysis is unable to explore causal effects of variation in income on the choice of contract, it allows for exploration of possible heterogeneity in, e.g., price responsiveness. Marginal effects of the fixed and variable price for different income levels are illustrated in Figures 8 and 9 Evidently, the immediate effect of the fixed price is relatively homogeneous across income groups, whereas the immediate effect of the variable price 
is insignificantly different from zero for most households, and only significantly positive for households living in high-income areas. One explanation for this result might be that high-income households can more easily afford potential transaction costs and therefore can respond to prices to a larger extent than low-income households. Finally, state dependence is substantial and the effect of the fixed price is larger than the effect of the variable price (in absolute magnitude) for all income groups.

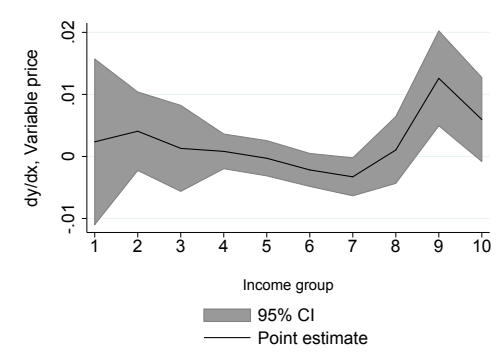

Figure 8: Marginal effects of the variable price, by income group. Both point estimates and $95 \%$ confidence intervals are illustrated. Zipcode data are used to define income groups.

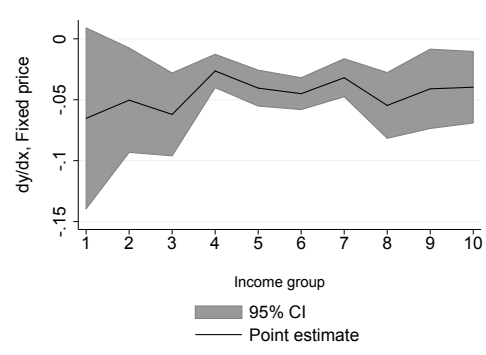

Figure 9: Marginal effects of the fixed price, by income group. Both point estimates and $95 \%$ confidence intervals are illustrated. Zip-code data are used to define income groups.

It is also of interest to explore heterogeneity in price responsiveness across levels of electricity usage. For example, even if many determinants of electricity usage are fixed in the short run and therefore most likely not a reason to switch from one contract type to another, households may still differ in price responsiveness across electricity usage levels. A household in an electrically heated villa, using substantially more electricity than a flat, might feel vulnerable to price shocks and therefore be more responsive to price variation. On the other hand, it might be the case that households living in villas have higher income and more easily can afford price spikes, therefore responding less to prices. This can be explored by estimating the model outlined in Section 4 separately for villas with electric heating, villas without electric heating, and flats. I find that the state dependence is similar across housing types, ranging from 0.95 for flats to 0.97 for electrically heated villas. Similarly, the marginal effect of the variable price is close to zero for all housing types. The response to variations in the fixed price differs somewhat across housing types, with an estimated marginal effect of -0.057 for flats, -0.037 for non-electrically heated villas and -0.011 for electrically heated villas. I have also estimated the model separately for different postal areas to explore regional differences in state dependence and price responsiveness. In short, results are very similar across postal areas, with substantial state dependence and very small effects of prices. 
Several alternative specifications and estimation frameworks are explored to test the robustness of the results. Robustness tests are discussed below, and results from these models are available upon request.

First, I have estimated the parameters in the model using different definitions of prices, such as the standard deviation of the variable price (e.g., over the last 12 months) as well as the maximum price (again, over the last 12 months). I have also estimated the model using the relative price between the variable and the fixed price. Further, I have included up to 12 lags of the variable price. For comparison, results from the latter specification are found in the Appendix. The results are robust to all these specifications. In particular, the state dependence is substantial and the effect of prices is small.

Second, recall that the panel data is unbalanced, with some attrition to other suppliers. It might be the case, for example, that households that are very price sensitive also are more likely to switch between different retailers (i.e., sample attrition). As a robustness check, I have estimated the parameters in the model using a balanced sub-set of the data. This sub-set includes only households that are observed every month from June 2010 to June 2014 (roughly 10000 households). Results are again very similar, with even greater state dependence (the estimated marginal effect of a fixed-price contract in the previous period is 0.98 ) and negligible effects of prices. Using the balanced sub-set, I have also estimated a Heckman model (Heckman (1981)) using household characteristics as exogenous instruments in the reduced form equation for the initial value of the latent variable. The Heckman model is estimated using the redprob command in Stata 14; see Stewart (2006). As in the other robustness specifications, results are very similar to the main specification. The framework suggested by Orme (1999) also gives similar results with substantial state dependence.

Third, remember that households on fixed-price contracts face a penalty if they wish to switch to a variable-price contract before the end of the contract period, and all households switching from a fixed-price contract to a variableprice contract do so at the end of their contract period. However, any attempt to account for contract duration (e.g., by the inclusion of some measurement of the penalty) is problematic because such a variable will be zero for all households on variable-price contracts, and therefore will perfectly predict such outcomes. One simple way of addressing this asymmetric switching is to assume that households on fixed-price contracts only consider switching contracts when the penalty is zero. Months for which the penalty fee is non-zero (i.e., the remaining contract duration is zero) can then be dropped from the data, and the parameters can be estimated using only data from such "choice periods". Results are qualitatively similar to the main specification, although the state dependence is somewhat smaller, with an estimated marginal effect of 0.76 , whereas the effects of prices are similar to the estimates in the main specification. I have also explored other definitions of "choice periods", e.g., assuming that households consider switching when they receive the bill for the previous months. Roughly half of the households have 12 bills per year, and the other half have six bills per year. Households themselves decide on billing frequency. In addition, I also estimate the model defining every sixth or twelfth month as a choice period, 
starting from the month when they signed their contract. Results are very similar across different definitions of choice periods.

Fourth, to explore whether the estimated state dependence differs depending on contract duration (for fixed-price contracts), I have estimated the model excluding contracts with duration longer than one year, and the findings of very large state dependence and small effects of prices remain.

\section{Conclusion}

In this paper, I have explored households' choice of electricity contract, and in particular the role of prices and previous contract choice. Using unique monthly panel data with detailed information about prices and contract choice for roughly 54000 households, I estimate a dynamic random effects probit with electricity contract choice as the dependent variable, and prices, temperature and previous choice of contract as independent variables. Endogeneity of the initial condition is accounted for using the approach suggested by Wooldridge (2005). I find that the electricity contract choice exhibits substantial state dependence, and that the previous contract choice to a very large extent determines the current choice. In contrast, prices have very small marginal effects. The results are robust to different specifications. Further, households are relatively homogeneous across income groups in terms of price responsiveness and state dependence. Given that so few households switch contracts each year, these results are expected. There are several plausible explanations for these results, including that many variables plausibly associated with contract choice are relatively constant in the short run, and that there may exist transaction costs and other barriers to switching that to a large extent prevent households from switching between contracts.

The conclusion to draw from these results is that households for some reasons do not respond to prices by switching between contracts. In particular, households appear to remain on their current contract, irrespective of prices. Although previous literature on determinants of electricity contract choice is sparse, the finding that households do not respond to prices by switching contracts is in line with previous literature on electricity demand, where the price elasticity of electricity typically is found to be small and households are argued to be inattentive to electricity prices.

The results in this paper have some important policy implications. For example, if policy makers want households to switch more frequently, e.g., in order to decrease market power for retailers, they should put effort into providing information about potential cost savings, as well as work to decrease switching costs and other barriers to switching. Removing barriers to switching may also increase price responsiveness if households switch to variable-price contracts. Some measures of this sort have already been taken, most notably with several websites providing information and guidance on prices and how to switch between contracts and/or retailers. However, the results in this paper suggest that such measures have had little effect, because the state dependence is substantial. 
Furthermore, if households were price responsive and to a large extent switched from variable-price contracts to fixed-price contracts after price peaks, the aggregate price responsiveness would decrease as more households switched to fixed-price contracts with less incentives to short-run price responsiveness. The results in this paper suggest that this is not the case, and that households will remain on their current contract even if price volatility increases, and that the share of households on each type of contract will remain similar in the short run even if there is price variation during some periods. Also note that the substantial state dependence might suggest that few households will switch to real-time pricing contracts even if households might reduce electricity costs on such contracts.

The results in this paper, while novel and plausible, suffer from a few datarelated drawbacks. In particular, the limited geographical variation in the sample calls for some caution when extrapolating the results to the entire Swedish population. Similarly, a longer time period of data would obviously be preferable to explore the dynamics of contract choice. The lack of variation at the household level for some socio-economic variables is an obvious drawback of the data; the other hand, many of the unobserved characteristics typically have limited short-term variation, and are therefore argued to have little effect on the choice of contract in the short run. Further, the results presented in this paper are robust to different specifications and the results are intuitive and plausible. Finally, this data provides a unique opportunity to explore electricity contract choice, and the results in this paper should be thought of as establishing a baseline for further research on this topic.

\section{Acknowledgments}

Thanks to Runar Brännlund, Chandra B. Kiran Krishnamurthy, Gauthier Lanot, Andrius Kažukauskas, Alejandro Eguez and seminar participants at Energimarknadsinspektionen, The Economic Policy Network and the 6th Ammarnäs CERE Workshop for feedback and fruitful discussions that helped to improve the paper. Also thanks to Skelleftea Kraft for providing the data used in the analysis. All remaining errors are mine.

\section{References}

Akay, A. (2009). The Wooldridge method for the initial values problem is simple: what about performance? IZA Discussion Paper.

Allcott, H. (2011). Consumers' perceptions and misperceptions of energy costs. The American Economic Review, 101(3):98-104.

Arulampalam, W. and Stewart, M. B. (2009). Simplified implementation of the Heckman estimator of the dynamic probit model and a comparison with al- 
ternative estimators. Oxford Bulletin of Economics and Statistics, 71(5):659681.

Astaneh, M. F. and Chen, Z. (2013). Price volatility in wind dominant electricity markets. In Eurocon, 2013 IEEE, pages 770-776. IEEE.

Borenstein, S. (2012). The redistributional impact of nonlinear electricity pricing. American Economic Journal: Economic Policy, 4(3):56-90.

Campbell, J. Y. and Cocco, J. F. (2003). Household risk management and optimal mortgage choice. Quarterly Journal of Economics, 118(4):1449-1494.

Chamberlain, G. (1980). Analysis of covariance with qualitative data. The Review of Economic Studies, 47(1):225-238.

Defeuilley, C. (2009). Retail competition in electricity markets. Energy Policy, $37(2): 377-386$.

Dhillon, U. S., Shilling, J. D., and Sirmans, C. (1987). Choosing between fixed and adjustable rate mortgages: Note. Journal of Money, Credit and Banking, 19(2):260-267.

Ek, K. and Söderholm, P. (2008). Households' switching behavior between electricity suppliers in Sweden. Utilities Policy, 16(4):254-261.

Energimyndigheten (2014). Electricity usage in small houses (Slutlig anvädning, småhus). Technical report.

Ericson, T. (2011). Households self-selection of dynamic electricity tariffs. Applied Energy, 88(7):2541-2547.

Gamble, A., Juliusson, E. A., and Gärling, T. (2009). Consumer attitudes towards switching supplier in three deregulated markets. The Journal of Socio-Economics, 38(5):814-819.

Gärling, T., Gamble, A., and Juliusson, E. A. (2008). Consumers' switching inertia in a fictitious electricity market. International Journal of Consumer Studies, 32(6):613-618.

Goett, A. A., Hudson, K., and Train, K. E. (2000). Customers' choice among retail energy suppliers: The willingness-to-pay for service attributes. The Energy Journal, 21(4):1-28.

Heckman, J. J. (1981). The incidental parameters problem and the problem of initial conditions in estimating a discrete time-discrete data stochastic process. In Analysis of Discrete Data with Econometric Applications, pages 114178. MIT Press.

Ito, K. (2014). Do consumers respond to marginal or average price? Evidence from nonlinear electricity pricing. The American Economic Review, 104(2):537-563. 
Juliusson, E. A., Gamble, A., and Garling, T. (2007). Loss aversion and price volatility as determinants of attitude towards and preference for variable price in the Swedish electricity market. Energy Policy, 35(11):5953-5957.

Kažukauskas, A. and Broberg, T. (2015). Perceptions and inattention in private electricity consumption. CERE-the Center for Environmental and Resource Economics, working paper: 2016-2.

Ketterer, J. C. (2014). The impact of wind power generation on the electricity price in Germany. Energy Economics, 44:270-280.

Klemperer, P. (1987). Markets with consumer switching costs. The Quarterly Journal of Economics, 102(2):375-394.

Konsumentverket (2009). Customer mobility - examples of restrictions for consumers (Kundrörlighet - exempel på hinder för konsumenter inom några viktiga marknader). Technical report, Konkurrensverket.

Krishnamurthy, C. K. B. and Kriström, B. (2015). A cross-country analysis of residential electricity demand in 11 OECD-countries. Resource and Energy Economics, 39:68-88.

Littlechild, S. (2006). Competition and contracts in the Nordic residential electricity markets. Utilities policy, 14(3):135-147.

Mundlak, Y. (1978). On the pooling of time series and cross section data. Econometrica, 46(1):69-85.

Nesbakken, R. (1999). Price sensitivity of residential energy consumption in norway. Energy Economics, 21(6):493-515.

Orme, C. (1999). Two-step inference in dynamic non-linear panel data models, manuscript. School of Economic Studies, University of Manchester.

Paiella, M. and Pozzolo, A. F. (2007). Choosing between fixed-and adjustablerate mortgages. In Household Credit Usage, pages 219-236.

Palmer, K. and Walls, M. (2015). Limited attention and the residential energy efficiency gap. The American Economic Review, 105(5):192-195.

Rabe-Hesketh, S. and Skrondal, A. (2013). Avoiding biased versions of Wooldridges simple solution to the initial conditions problem. Economics Letters, 120(2):346-349.

Revelt, D. and Train, K. (2000). Customer-specific taste parameters and mixed logit: Households' choice of electricity supplier. Department of Economics, $U C B$, working paper.

SCB (2014a). Prices on electricity and transmission of electricity (Priser på elenergi och överföring av el, månadsvärden). Technical report. 
SCB (2014b). Renegotiations and switching of electricity contracts (Omförhandling och byten av elavtal). Technical report, Statistics Sweden.

Skrondal, A. and Rabe-Hesketh, S. (2014). Handling initial conditions and endogenous covariates in dynamic/transition models for binary data with unobserved heterogeneity. Journal of the Royal Statistical Society: Series C (Applied Statistics), 63(2):211-237.

Stewart, M. B. (2006). redprob - a Stata program for the Heckman estimator of the random effects dynamic probit model. Stata Journal.

Stewart, M. B. (2007). The interrelated dynamics of unemployment and lowwage employment. Journal of Applied Econometrics, 22(3):511-531.

Sweco (2016). Economic conditions for different production technologies (Ekonomiska förutsättningar för skilda kraftslag). Technical report.

TEMO (2005). Change electricity supplier - The Swedish electricity market after the deregulation (Byte av elleverantör - den Svenska elmarknaden efter elmarknadsreformen). Technical report, Temo Svensk Energi.

Vesterberg, M. and Kiran B Krishnamurthy, C. (2016). Residential end use electricity demand: the implications for real time pricing in Sweden. Energy Journal, 37(4):141-164.

Woo, C.-K., Horowitz, I., Moore, J., and Pacheco, A. (2011). The impact of wind generation on the electricity spot-market price level and variance: The Texas experience. Energy Policy, 39(7):3939-3944.

Wooldridge, J. M. (2005). Simple solutions to the initial conditions problem in dynamic, nonlinear panel data models with unobserved heterogeneity. Journal of Applied Econometrics, 20(1):39-54.

Wooldridge, J. M. (2010). Econometric analysis of cross section and panel data. MIT press.

Yang, Y. (2014). Understanding household switching behavior in the retail electricity market. Energy Policy, 69:406-414. 


\section{A Appendix}

Table 4: Results of the dynamic random effects probit model with electricity contract (fixed price $=1$ ) as dependent variable and with 12 lags of the variable price

\begin{tabular}{|c|c|c|c|c|}
\hline & Coeff. & Std. Error & $\mathrm{dy} / \mathrm{dx}$ & Std. Error \\
\hline$y_{t-1}$ & 5.492 & 0.024 & 0.963 & 0.003 \\
\hline Temperature & 0.007 & 0.003 & 0.000 & 0.000 \\
\hline Fixed price $(\mathrm{SEK} / \mathrm{kWh})$ & -0.681 & 0.763 & -0.004 & 0.005 \\
\hline \multicolumn{5}{|l|}{ Variable price (SEK/kWh) } \\
\hline $\mathrm{t}-1$ & -0.277 & 0.129 & -0.001 & 0.000 \\
\hline $\mathrm{t}-2$ & -0.112 & 0.118 & -0.000 & 0.000 \\
\hline $\mathrm{t}-3$ & -0.502 & 0.113 & -0.003 & 0.000 \\
\hline $\mathrm{t}-4$ & -0.684 & 0.107 & -0.004 & 0.000 \\
\hline $\mathrm{t}-5$ & -1.414 & 0.121 & -0.009 & 0.000 \\
\hline $\mathrm{t}-6$ & 0.131 & 0.096 & 0.000 & 0.000 \\
\hline$t-7$ & 0.146 & 0.087 & 0.001 & 0.000 \\
\hline$t-8$ & 0.714 & 0.084 & 0.005 & 0.000 \\
\hline $\mathrm{t}-9$ & 0.454 & 0.081 & 0.003 & 0.000 \\
\hline$t-10$ & 1.100 & 0.098 & 0.007 & 0.000 \\
\hline $\mathrm{t}-11$ & -0.371 & 0.096 & -0.002 & 0.000 \\
\hline $\mathrm{t}-12$ & -0.199 & 0.101 & -0.001 & 0.000 \\
\hline Month dummies & Yes & & & \\
\hline Year dummies & Yes & & & \\
\hline Initial condition variables & Yes & & & \\
\hline Log-likelihood & -38654.603 & & & \\
\hline$\rho$ & 0.296 & & & \\
\hline No of obs & 1677405 & & & \\
\hline No of households & 54548 & & & \\
\hline Average $\mathrm{T}$ & 30.8 & & & \\
\hline
\end{tabular}


Table 5: Mean per-capita income by income group

\begin{tabular}{lll}
\hline \hline & Mean income (in SEK) & Number of households \\
\hline Income group 1 & 165000 & 577 \\
Income group 2 & 203000 & 1895 \\
Income group 3 & 222000 & 2169 \\
Income group 4 & 238000 & 8864 \\
Income group 5 & 254000 & 11640 \\
Income group 6 & 269000 & 12614 \\
Income group 7 & 288000 & 10222 \\
Income group 8 & 312000 & 2974 \\
Income group 9 & 351000 & 2206 \\
Income group 10 & 467000 & 1387 \\
& & \\
\hline \hline
\end{tabular}

